\title{
Identifying Key Influential Factors of Bid Evaluation in Government Public Project Green Procurement in China Using BP-DEMATEL Model
}

\author{
Yi Zhang $(1)$ and Qiang Chen $(1 D)$ \\ School of Economics and Management, Hubei University of Technology, Wuhan 430068, Hubei, China \\ Correspondence should be addressed to Yi Zhang; 20130031@hbut.edu.cn
}

Received 31 January 2022; Accepted 10 February 2022; Published 2 March 2022

Academic Editor: Filippo Cacace

Copyright (C) 2022 Yi Zhang and Qiang Chen. This is an open access article distributed under the Creative Commons Attribution License, which permits unrestricted use, distribution, and reproduction in any medium, provided the original work is properly cited.

\begin{abstract}
With the global resource and environment problems becoming increasingly prominent and the government procurement scale growing rapidly, the implementation of green procurement for government public project will have a significant impact on the protection of resources and environment. Identifying the key influential factors of bid evaluation in government public project green procurement is of great significance for promoting the construction of government public project green procurement system. Based on the Decision-Making Trial and Evaluation Laboratory (DEMATEL) method, Back Propagation (BP) neural network is introduced to determine the direct-relation matrix, optimizing the traditional DEMATEL method. This paper uses the BP-DEMATEL model to identify key influential factors of bid evaluation in government public project green procurement by algorithmic design. Among 56 indicators, which have formed a set of index system of bid evaluation in government public project green procurement, $20 \mathrm{key}$ influential factors are identified, providing reference for the government to implement green procurement in the field of public project. The research results not only enrich and improve the theoretical and practical research in the field of government public project green procurement, but also solve the defects of traditional DEMATEL method that the method is too subjective and tedious when obtaining the influence degree between each pair of factors to construct direct-relation matrix through questionnaire surveys or expert scoring method, thus expanding the scope of the application of the DEMATEL method.
\end{abstract}

\section{Introduction}

With the global resource and environment problems becoming increasingly prominent and the government procurement scale growing rapidly, government green procurement has become a worldwide trend. Government green procurement refers to the economic behavior of legally using fiscal funds to purchase green products, projects, and services [1], which is the entire process that one or more qualified suppliers are selected through tendering or other methods to accomplish green products, projects, and services under the guidance of green development concept. Wang Ying, Director of the Government Procurement Management Office of the State Treasury Department of the Ministry of
Finance, pointed that the Chinese government green procurement system is still in its infancy and it is of relatively small coverage at present, which is mainly reflected in the policies of compulsory procurement and prior procurement of energy-saving and environment-friendly products; however, projects involve less green procurement. From the existing research, the Chinese government procurement systems lack systematic and comprehensive standards of bid evaluation for public project green procurement. Therefore, identification of key influential factors of bid evaluation in government public project green procurement can provide theoretical guidance and methodological basis for the government to promote and improve the construction of government public project green procurement system. 
In China, government public project mainly focuses on infrastructure construction, while creating huge economic and social benefits for the society; they also consume a large number of natural resources and energy resources and cause irreversible serious pollution and damage to the environment, on which human beings depend. This paper is a systematic study on identifying the key influential factors of bid evaluation in government public project green procurement, which not only helps to save energy, protect environment, and bring great environmental benefits to society, but also helps to establish social image and give full play to government's leading role. It is of great practical significance for the government to carry out green procurement in the field of public project, construct and improve the green procurement system of government public project, and establish and improve the economic system of green and low-carbon circular development.

According to the website of the Ministry of Finance of the People's Republic of China released on September 3, 2021, the scale of Chinese government procurement in 2020 reached 3,697.06 billion yuan, which is 390.36 billion yuan more than the previous year, increasing by $11.8 \%$ and accounting for $10.2 \%$ of China's fiscal expenditure and $3.6 \%$ of Gross Domestic Product (GDP). The scale of project procurement was $1,749.24$ billion yuan, accounting for $47.3 \%$ of Chinese government procurement scale, as shown in Figure 1 . In addition, open tendering accounted for $79.3 \%$ of Chinese government procurement scale. It can be seen that the scale of project procurement will be in steady growth and still be in the dominate position in the short term. Open tendering will continue to be the main way of Chinese government procurement. To refine the research direction and clarify the research goals, this paper only conducts research on the bid evaluation in government public project green procurement that adopts open tendering.

This paper uses the BP-DEMATEL model to identify key influential factors of bid evaluation in government public project green procurement by algorithmic design. The key influential factors provide reference for the government to implement green procurement in the field of public project. The research results not only enrich and improve the theoretical and practical research in the field of government public project green procurement, but also solve the defects of traditional DEMATEL method that the method is too subjective and tedious when obtaining the influence degree between each pair of factors to construct direct-relation matrix through questionnaire surveys or expert scoring method, thus expanding the scope of the application of the DEMATEL method.

The following section is literature review. Section 3 is methodology. Section 4 is results and discussion. Finally, conclusions of this study are drawn.

\section{Literature Review}

As there are few studies specifically focused on the bid evaluation in government public project green procurement, this section mainly reviews the relevant literature from the following four aspects.

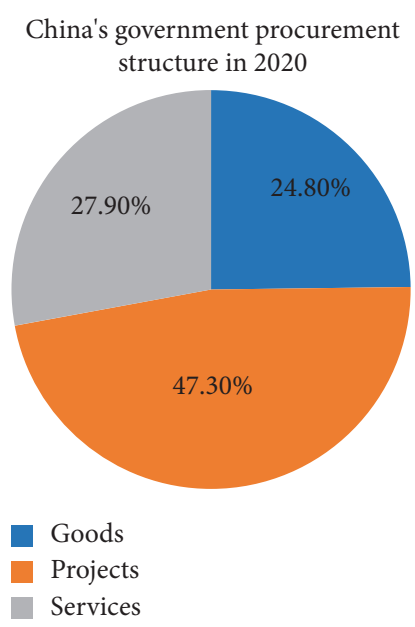

Figure 1: China's Government Procurement Structure in 2020 (data source: website of the Ministry of Finance of the People's Republic of China, September 3, 2021).

2.1. Research on Relevant Regulations of Government Public Project Procurement. "Regulations for the Implementation of the Government Procurement Law of the People's Republic of China" (hereinafter referred to as the "Regulations") came into effect on March 1, 2015. Paragraph 1 of Article 7 stipulates that the activity that government purchase project through tendering is subject to "Tendering and Bidding Law of the People's Republic of China" and its implementing regulations. Paragraph 2 of Article 7 of the "Regulations" stipulates that the project mentioned in Paragraph 1 refers to construction project, including the new-construction, reconstruction, expansion of buildings and structures, and their decoration, demolition, and repairment. Article 7 of the "Regulation" successfully achieved the cohesion and unification with the "Tendering and Bidding Law of the People's Republic of China" and its implementing regulations, maintaining the consistency of the law, avoiding disagreement in the application, and strengthening the legality of project procurement [2]. At present, rules and regulations on green procurement have not yet formed a system, and they are scattered in environmental protection and procurement-related laws and policies. "Government Procurement Law" and "Implementing Regulations of Government Procurement Law" govern Chinese government procurement activities, providing a policy and legal basis for the implementation of the public project green procurement system. However, only a few articles mention the issue of green procurement. There are no systemic green procurement regulations and there are structural and functional deficiencies as a whole [3]. For instance, Article 6 of the "Regulations" simply take the achievement of energy conservation and environment protection as the goal of public policy, there are no clear laws and specific measures on how to achieve energy saving, environmental protection, and green procurement promotion, and there is a lack of rules on measures to deal with non-green procurement behaviors [4]. 
2.2. Theoretical and Practical Research on Green Procurement of Government Public Project. Government green procurement refers to the economic behavior of legally using fiscal funds to purchase green products, projects, and services. In terms of theoretical research, most scholars mainly discuss the theoretical basis of government green procurement from the aspects of new institutional economics, environmental economics, environmental management, and sustainable development theory [5]. Specifically, government green procurement activities are mainly guided by externality theory, green supply chain management theory, sustainable development theory, and stakeholder theory [6-8]. At present, the theoretical research on green procurement in China is mainly for government procurement and manufacturing procurement; the research content mainly focuses on green supplier selection [9-15], green procurement management mode [16], restriction factor analysis [17-19], legal system [20-22], policy recommendations [23-26], etc., while the research on green supplier selection mainly focuses on goods [27], and research focuses on projects of government green procurement is rare. In terms of practical research, in recent years, some progress has been made in green procurement of government public project. Whether it is the construction of the Beijing's Olympic facilities or the Shanghai World Expo Hall, a new model of green procurement has been implemented from the designer to the constructor [28]. Some local governments are formulating green procurement regulations in the field of public project; for example, the Legal System Office of the People's Government of Changzhou City, Jiangsu Province, announced the "Guidelines on Accelerating Green Procurement of Government-Invested Projects in the Engineering Construction Field (Consultation Draft)," which is recognized as the first public project green procurement guideline by experts [29] (China Government Procurement News, July 24, 2015).

\subsection{Research on Green Index System of Bidding Evaluation in} Project Procurement. There is very limited research on green index system of bidding evaluation in project procurement; only Li [30-32], Yang [33], Li [34], Zhang [35, 36], etc. conducted research. It is $\mathrm{Li}$ [30-32] who first constructed an index system of bid evaluation for green construction, including three categories of indicators: qualification, technology, and economy; Yang [33] constructed an evaluation index system of contractor selection for EPC projects based on green concept, including four categories of indicators: design plan, construction plan, procurement plan, and management measures; $\mathrm{Li}$ [34] constructed an evaluation index system for building contractor green construction capacity, including four categories of indicators: qualification, green construction technology, organizational management, and economy; Zhang [35] constructed a green index system of bid evaluation for engineering projects from four aspects of qualification, technology, economy, and management; Zhang [36] constructed a bid evaluation index system for government public project green procurement from five aspects of qualification, economy, technology, management, and public welfare.
2.4. Research on Identification Methods of Key Influential Factors. Most scholars used DEMATEL model for research [37-42], and some experts and scholars also combined two or more mathematical models based on previous studies, such as AHP-DEMATEL model [43], Fuzzy-DEMATEL model [44, 45], Grey-DEMATEL model [46, 47], DEMATEL-ANP model [48], COWA-DEMATEL model [49], DEMATEL-TOPSIS model [50], DEMATEL-COPRAS model [51], DEMATEL-ISM model [52-55], and DEMATEL-ISM-MICMAC model [56]. To a certain extent, they have enriched the theoretical and practical research on the identification methods of key influential factors.

In summary, there are three aspects to be further improved. (1) The current research on green procurement is mainly for government procurement and manufacturing procurement, and the research on green supplier selection mainly focuses on goods, while research focuses on projects of government green procurement is rare; (2) in the green procurement management of public project, the selection of green bidders is the key to improve the government green procurement performance and public project green performance. However, the Chinese government procurement system lacks systematic and complete standards of bid evaluation in public project green procurement; (3) identification of the key influential factors is less scientific. Most scholars use the traditional DEMATEL method to identify the key influential factors. However, as for many complex problems with lots of influential factors, it is difficult to obtain data of the influence degree between each pair of factors to construct direct-relation matrix through questionnaire surveys or experts scoring method, which greatly limits the application scope of the DEMATEL method. In addition, the use of questionnaire surveys or expert scoring method to obtain the influence degree between each pair of factors is highly dependent on the knowledge and experience of the survey participants, which relatively affects the objectivity and reliability of the research conclusions. By summarizing related research [57-61], based on the DEMATEL method, BP neural network is introduced to determine the direct-relation matrix, optimizing the traditional DEMATEL method. This paper uses the BPDEMATEL model to identify key influential factors of bid evaluation in government public project green procurement by algorithmic design, so as to promote the theoretical and practical research of the government public project green procurement system.

\section{Methodology}

3.1. BP-DEMATEL Model. DEMATEL [62] is a method to analyze the cause-effect relationship between factors in complex systems and identify key factors. In this method, the direct-relation matrix is established based on the influence degree between each pair of factors in the system, the comprehensive influence matrix is calculated, the affecting degree and affected degree of each factor are calculated, and then the center degree and cause degree of each factor are determined. However, the direct-relation matrix in the DEMATEL method is mainly determined through 
questionnaire surveys or expert scoring method, which depends on the knowledge and experience of the survey participants, thus relatively reducing the objectivity and reliability of the research conclusions. In addition, it is difficult and tedious to analyze the complex research objects with lots of influential factors. By introducing the BP neural network [63] to the DEMATEL method, the direct-relation matrix can be calculated by the BP neural network; then the influential factors can be analyzed and identified through the DEMATEL method. As for processing complex research objects with lots of influential factors, BP-DEMATEL model possesses convenience and operational feasibility. And the method overcomes subjectivity when using questionnaire surveys or expert scoring method as well. Therefore, the analysis of influential factors is more objective and reliable.

The BP neural network is used to establish a nonlinear mapping relationship from the input layer to the output layer, the neural network is trained by the momentum adaptive learning rate gradient descent method, the weights and thresholds of the network are continuously adjusted to minimize the error function, the weight matrix between the input layer and the hidden layer and the weight vector between the hidden layer and the output layer are obtained, and the overall weight vector between the input layer and the output layer is calculated, from which the direct-relation matrix is obtained. Through the DEMATEL method, the comprehensive influence matrix can be determined based on the direct-relation matrix, the affecting degree and affected degree of each factor are calculated, and then the center degree and cause degree of each factor are calculated. The Cartesian coordinate system is establish based on the center degree and cause degree of each factor, the cause-effect diagram is drawn with the center degree as the abscissa and the cause degree as the ordinate, and the position of each factor is marked on the coordinate system. With the help of the cause-effect diagram, the factors can be separated into a cause group and an effect group. Additionally, the key factors of a complex system can be identified.

3.2. Calculation Steps of BP-DEMATEL. The flow diagram of the BP-DEMATEL model is shown in Figure 2.

The specific calculation steps of the BP-DEMATEL model are as follows.

Step 1. Construct the influential factor matrix $x$ and the target factor matrix $y$ :

$$
\begin{aligned}
x & =\left(x_{i k}\right)_{m \times p}(i=1,2, \ldots m ; k=1,2, \ldots p) y \\
& =\left(y_{1 k}\right)_{1 \times p}(k=1,2, \ldots p) .
\end{aligned}
$$

Among them, $m$ represents the number of influential factors, $p$ represents the number of statistical samples, and there is only one target factor.

$x_{i k}$ is the rating value of the $i$-th influential factor for the $k$-th sample, and $y_{1 k}$ is the rating value of the target factor for the $k$-th sample, i.e., the comprehensive evaluation result for the $k$-th sample. 1, 2, 3, 4, and 5 represent very poor, poor, fair, good, and excellent, respectively.
Step 2. Standardize the influential factor matrix $x$ and the target factor matrix $y$ :

$$
x, y \Rightarrow \bar{x}, \bar{y}, \bar{x}_{i k}=\frac{x_{i k}-\mu_{i x}}{\sigma_{i x}}, \bar{y}_{1 k}=\frac{y_{1 k}-\mu_{y}}{\sigma_{y}} .
$$

In the equation, $\bar{x}=\left(\bar{x}_{i k}\right)_{m \times p}(i=1,2, \cdots m$; $k=1,2, \ldots p)$ represents standardized matrix of the influential factor matrix $x, \bar{y}=\left(\bar{y}_{1 k}\right)_{1 \times p}(k=1,2, \ldots p)$ represents standardized matrix of the target factor matrix $y, \mu_{i x}$ represents the sample mean of the $i$-th influential factor, $\sigma_{i x}$ represents the sample standard deviation of the $i$-th influential factor, $\mu_{y}$ represents the sample mean of the target factor, and $\sigma_{y}$ is the sample standard deviation of the target factor. The standardization process not only converts the raw data into standardized values without differences in dimensions or orders of magnitude, eliminating the influence of different factors due to different attributes, thus facilitating the comprehensive analysis and comparison of influential factors of different dimensions or orders of magnitude, but also accelerates the convergence speed of the algorithm.

Step 3. Calculate the weight matrix.

Let $\bar{x}$ be the input matrix of the BP neural network and $\bar{y}$ be the output vector of the $\mathrm{BP}$ neural network. Use the momentum adaptive learning rate gradient descent method to train the BP neural network. Calculate the weight matrix $W_{m \times g}$ between the input layer and the hidden layer, and the weight vector $w_{g \times 1}$ between the hidden layer and the output layer. Among them, $g$ represents the number of hidden layer neurons.

Step 4. Calculate the overall weight vector:

$$
\omega=\left|W_{m \times g}\right| \cdot\left|w_{g \times 1}\right|=\left(\omega_{1}, \omega_{2}, \ldots, \omega_{m}\right)^{T} .
$$

Among them, $\omega$ represents the overall weight vector between the input layer and the output layer and $\left|W_{m \times g}\right|$, $\left|w_{g \times 1}\right|$ means taking the absolute value for each element in the weight matrix.

Step 5. Construct the direct-relation matrix A:

$$
A=\left(a_{i j}\right)_{m \times m}=\left(\begin{array}{cccc}
a_{11} & a_{12} & \cdots & a_{1 m} \\
a_{21} & a_{22} & \cdots & a_{2 m} \\
\vdots & \vdots & \ddots & \vdots \\
a_{m 1} & a_{m 2} & \cdots & a_{m m}
\end{array}\right) .
$$

Among them, $a_{i i}=0, a_{i j}=\left(\omega_{i} / \omega_{j}\right)\left(i f \omega_{j}=0\right.$, then $a_{i j}=0$ ). The element $a_{i j}$ in direct-relation matrix represents the direct influence degree of factor $i$ on factor $j$, expressed by the ratio of the weight of factor $i \omega_{i}$ to the weight of factor $j \omega_{j}$. There is not only a direct influence relationship between factors, but also an indirect influence relationship. In order to analyze the indirect influence between the factors, a comprehensive influence matrix requires to be calculated. 

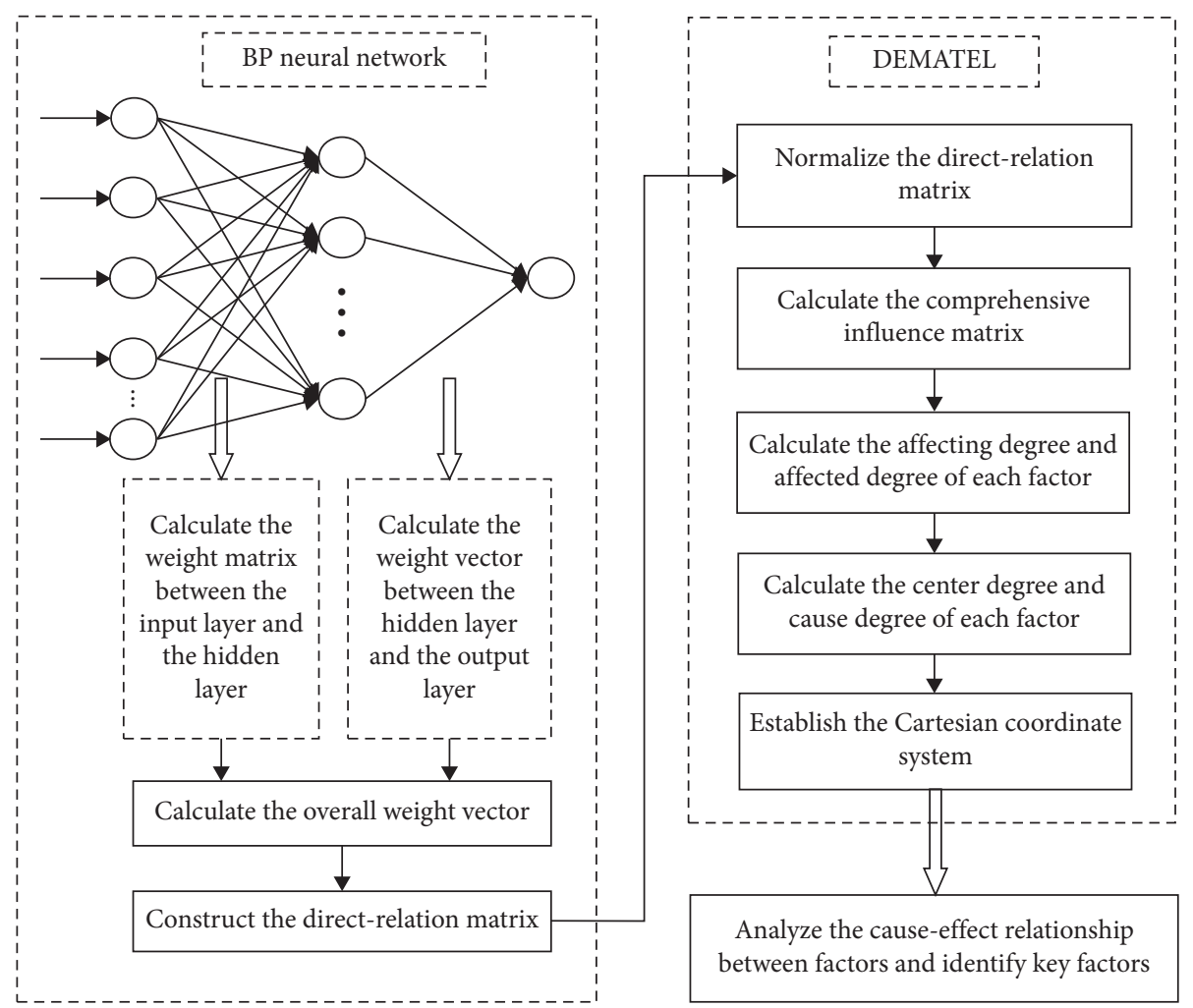

FIgUre 2: The flow diagram of the BP-DEMATEL model.

Step 6. Normalize the direct-relation matrix A to obtain the matrix B:

$$
B=\left(b_{i j}\right)_{m \times m}=\frac{1}{\max _{1 \leq i \leq m} \sum_{j=1}^{m} a_{i j}} \cdot A .
$$

Step 7. Calculate the comprehensive influence matrix T:

$$
T=\left(t_{i j}\right)_{m \times m}=B(E-B)^{-1} .
$$

Among them, $(E-B)^{-1}$ is the inverse matrix of $(E-B)$ and $E$ is the unit matrix.

The element $t_{i j}$ in the comprehensive influence matrix indicates the degree of direct and indirect influence of factor $i$ on factor $j$, or the comprehensive influence degree to which factor $j$ is affected by factor $i$.

Step 8. Calculate the affecting degree and affected degree of each factor.

Calculate the sum of each row and each column of T. D is the sum of the rows of $T$, which is defined as the affecting degree. $R$ is the sum of the columns of $T$, which is defined as the affected degree. $D$ and $R$ can be calculated as follows.

Step 9. Calculate the center degree and cause degree of each factor.

$u$ is the sum of the affecting degree $D$ and affected degree $R$, which is defined as the center degree. $v$ is the difference between the affecting degree $D$ and affected degree $R$, which is defined as the cause degree.

$$
\begin{aligned}
& u_{i}=D_{i}+R_{i}, \\
& v_{i}=D_{i}-R_{i} .
\end{aligned}
$$

The center degree indicates the importance of the factor; the larger the value, the greater the importance of the factor. The cause degree can be used to distinguish whether the type of factor is a cause factor or an effect factor. If the cause degree is positive $\left(v_{i}>0\right)$, the factor falls under the cause group; if the cause degree is negative $\left(v_{i}<0\right)$, the factor will be grouped into the effect group.

\section{Results and Discussion}

4.1. Construction of Index System of Influential Factors. The research of this paper is to continue and deepen the existing research results. The authors have constructed a set of index systems of bid evaluation in government public project green procurement, including 56 indicators [32]. Bid evaluation in government public project green procurement is a complex organic system. This paper uses the BPDEMATEL model to systematically analyze the cause-effect relationship between factors and identify key influential factors, further optimizing the structure of the bid evaluation system.

4.2. Data Collection and Calculation Results. Select 150 valid questionnaires, and use MATLAB 2018a to calculate the center degree and cause degree of each factor. The specific results are shown in Table 1 . 
TABle 1: Center degree and cause degree of each factor.

\begin{tabular}{|c|c|c|c|}
\hline Code & Factors & Center degree & Cause degree \\
\hline 1 & Qualification level & 2.78256 & -0.40013 \\
\hline 2 & Enterprise size & 2.75536 & 0.09738 \\
\hline 3 & Registered capital & 2.75887 & 0.16971 \\
\hline 4 & Working capital & 2.75878 & -0.16838 \\
\hline 5 & Financial ability & 3.03586 & -1.27824 \\
\hline 6 & Financial soundness & 2.75795 & -0.15403 \\
\hline 7 & Contract performance & 2.78029 & -0.38400 \\
\hline 8 & Litigation or arbitration & 2.75460 & 0.07262 \\
\hline 9 & Past excellent engineering performance & 2.77743 & -0.36277 \\
\hline 10 & Construction in progress and new undertakings & 2.75448 & -0.06794 \\
\hline 11 & Construction experience of similar project & 2.90030 & 0.91062 \\
\hline 12 & Green construction demonstration project & 3.07292 & 1.36394 \\
\hline 13 & Total bid price & 3.14606 & -1.52156 \\
\hline 14 & Unit price of main items & 2.76202 & -0.21503 \\
\hline 15 & Quotation for sporadic project & 2.76029 & 0.19142 \\
\hline 16 & Reasonability of quotation composition & 2.97614 & 1.12909 \\
\hline 17 & Payment terms & 2.97293 & -1.12063 \\
\hline 18 & Environmental governance costs & 2.95176 & 1.06318 \\
\hline 19 & Green investment costs & 2.94286 & 1.03822 \\
\hline 20 & Full life cycle operating costs & 2.85907 & 0.76924 \\
\hline 21 & Construction period & 3.10734 & 1.43981 \\
\hline 22 & Duration reasonability & 2.75786 & -0.15248 \\
\hline 23 & Construction schedule and guarantee measures & 2.91643 & 0.96075 \\
\hline 24 & Quality management system and assurance measures & 2.80960 & -0.55794 \\
\hline 25 & Technical strength & 2.78457 & 0.41391 \\
\hline 26 & Construction plan and technical measures & 2.91003 & -0.94114 \\
\hline 27 & Quality and quantity of labor & 2.75783 & 0.15195 \\
\hline 28 & Material quality & 2.75631 & 0.12137 \\
\hline 29 & Mechanical equipment level & 2.75537 & 0.09758 \\
\hline 30 & Water saving and water resource utilization measures & 3.00386 & -1.20028 \\
\hline 31 & New water-saving technology implementation plan & 2.76936 & -0.29462 \\
\hline 32 & Safe water implementation plan & 2.76641 & -0.26550 \\
\hline 33 & Site utilization & 2.76542 & 0.25502 \\
\hline 34 & Reasonability of construction layout & 2.76402 & 0.23933 \\
\hline 35 & Land saving and land resource utilization measures & 2.99154 & -1.16909 \\
\hline 36 & Proportion of green materials use & 2.78787 & -0.43555 \\
\hline 37 & Material saving and material resource utilization measures & 2.97797 & -1.13391 \\
\hline 38 & Proportion of recyclable materials reuse & 2.75376 & -0.02605 \\
\hline 39 & Proportion of local materials & 2.75366 & 0.01088 \\
\hline 40 & Proportion of clean energy use & 2.78499 & 0.41667 \\
\hline 41 & Energy saving and energy utilization measures & 2.97706 & -1.13153 \\
\hline 42 & New energy-saving technology implementation plan & 2.75993 & -0.18627 \\
\hline 43 & Planning and control capacity & 2.85073 & 0.73765 \\
\hline 44 & Organization and coordination capacity & 2.81496 & -0.58433 \\
\hline 45 & Green construction management system & 3.03599 & 1.27856 \\
\hline 46 & Green education and cultural construction & 2.81383 & -0.57888 \\
\hline 47 & Health protection for construction laborers & 2.80398 & -0.52895 \\
\hline 48 & Wage protection for construction laborers & 2.79741 & 0.49290 \\
\hline 49 & Humanistic care for construction laborers & 2.89285 & -0.88661 \\
\hline 50 & Safety management system and measures & 2.85937 & 0.77036 \\
\hline 51 & Safety measures for mechanical facilities & 2.75385 & -0.03404 \\
\hline 52 & Personal safety measures & 2.75381 & 0.03022 \\
\hline 53 & Dust control measures & 2.77434 & 0.33831 \\
\hline 54 & Sewage discharge control measures & 2.79607 & 0.48526 \\
\hline 55 & Soil protection and construction waste control measures & 2.78800 & 0.43639 \\
\hline 56 & Noise control and light pollution control measures & 2.76967 & 0.29750 \\
\hline
\end{tabular}

Draw the cause-effect relationship diagram with the center degree as the abscissa and the cause degree as the ordinate, as shown in Figure 3.
Figure 3 shows the cause-effect relationship diagram of 56 influential factors of bid evaluation in government public project green procurement, with the center degree as the 


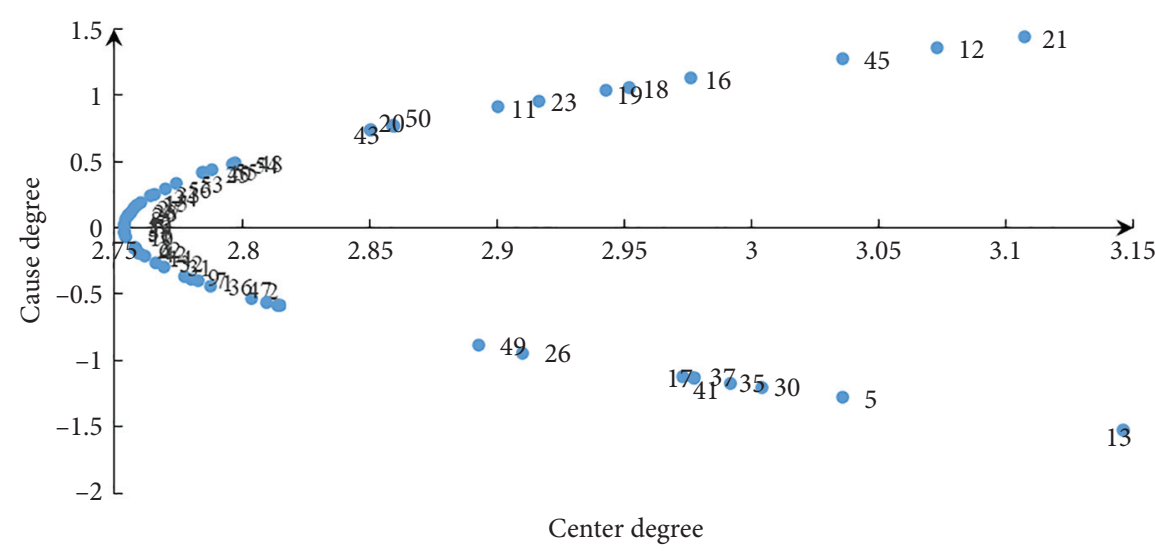

Figure 3: Cause-effect relationship diagram.

abscissa and the cause degree as the ordinate. In terms of cause degree, points with vertical coordinate above 0 are cause factors; the sequence numbers of the 11 factors with the largest cause degree (cause degree $>0.7$ ) are $21,12,45,16,18,19,23$, $11,50,20$, and 43 . The points with vertical coordinate below 0 are the effect factors; the serial numbers of the 9 factors with the largest absolute value of cause degree (cause degree $<-0.7$ ) are $13,5,30,35,37,41,17,26$, and 49 . In terms of center degree, the serial numbers of the 20 factors with the largest value of center degree (center degree $>2.85$ ) are $13,21,12,45,5,30,35,37,41$, $16,17,18,19,23,26,11,49,50,20$, and 43 .

\subsection{Result Analysis and Discussion}

4.3.1. Identification of Cause Factors. From Table 1 and Figure 3, there are 29 cause factors among the 56 influential factors, since their cause degree is greater than zero (cause degree $>0$ ). As shown in Table 2 , the sequence numbers of cause degree in descending order are $21,12,45,16,18,19,23$, $11,50,20,43,48,54,55,40,25,53,56,33,34,15,3,27,28,29$, $2,8,52$, and 39 . It can be illustrated that they are more inclined to affect other factors. Among them, the sequence numbers of the 11 factors with the largest cause degree (cause degree $>0.7$ ) are 21 (construction period), 12 (green construction demonstration project), 45 (green construction management system), 16 (reasonability of quotation composition), 18 (environmental governance costs), 19 (green investment costs), 23 (construction schedule and guarantee measures), 11 (construction experience of similar project), 50 (safety management system and measures), 20 (full life cycle operating costs), and 43 (planning and control capacity). It can be explained that these 11 cause factors have more intensive impact on other factors.

4.3.2. Identification of Effect Factors. From Table 1 and Figure 3, there are 27 effect factors among the 56 influential factors, since their cause degree is lower than zero (cause degree $<0$ ). As shown in Table 3 , the sequence numbers of the absolute value of cause degree in descending order are 13, 5, $30,35,37,41,17,26,49,44,46,24,47,36,1,7,9,31,32,14,42$, $4,6,22,10,51$, and 38 . It can be illustrated that they are more inclined to be affected by other factors. Among them, the sequence numbers of the 9 factors with the largest absolute value of cause degree (cause degree $<-0.7$ ) are 13 (total bid price), 5 (financial ability), 30 (water saving and water resource utilization measures), 35 (land saving and land resource utilization measures), 37 (material saving and material resource utilization measures), 41 (energy saving and energy utilization measures), 17 (payment terms), 26 (construction plan and technical measures), and 49 (humanistic care for construction laborers). It can be explained that other factors have more intensive impact on these 9 effect factors.

4.3.3. Identification of Key Influential Factors. Take the center degree as the basis for judging the importance of factors. According to Table 1, sort the factors in the descending order of center degree. Select 20 factors with center degree greater than the average 2.84244 as the key influential factors; the serial numbers of the importance degree in descending order are 13 (total bid price), 21 (construction period), 12 (green construction demonstration project), 45 (green construction management system), 5 (financial ability), 30 (water saving and water resource utilization measures), 35 (land saving and land resource utilization measures), 37 (material saving and material resource utilization measures), 41 (energy saving and energy utilization measures), 16 (reasonability of quotation composition), 17 (payment terms), 18 (environmental governance costs), 19 (green investment costs), 23 (construction schedule and guarantee measures), 26 (construction plan and technical measures), 11 (construction experience of similar project), 49 (humanistic care for construction laborers), 50 (safety management system and measures), 20 (full life cycle operating costs), and 43 (planning and control capacity), as shown in Table 4

According to the research results, the 20 key influential factors of bid evaluation in government public project green procurement and their importance ranking (in order of centrality degree) are largely in line with the actual situation, proving the validity of this paper's methodology.

4.3.4. Comparative Analysis of BP-DEMATEL Model and Traditional DEMATEL Method. The traditional DEMATEL method depends on questionnaire surveys or expert scoring 
TAble 2: Cause factors.

\begin{tabular}{|c|c|c|}
\hline Code & Cause factors & Cause degree $(>0)$ \\
\hline 21 & Construction period & 1.43981 \\
\hline 12 & Green construction demonstration project & 1.36394 \\
\hline 45 & Green construction management system & 1.27856 \\
\hline 16 & Reasonability of quotation composition & 1.12909 \\
\hline 18 & Environmental governance costs & 1.06318 \\
\hline 19 & Green investment costs & 1.03822 \\
\hline 23 & Construction schedule and guarantee measures & 0.96075 \\
\hline 11 & Construction experience of similar project & 0.91062 \\
\hline 50 & Safety management system and measures & 0.77036 \\
\hline 20 & Full life cycle operating costs & 0.76924 \\
\hline 43 & Planning and control capacity & 0.73765 \\
\hline 48 & Wage protection for construction laborers & 0.49290 \\
\hline 54 & Sewage discharge control measures & 0.48526 \\
\hline 55 & Soil protection and construction waste control measures & 0.43639 \\
\hline 40 & Proportion of clean energy use & 0.41667 \\
\hline 25 & Technical strength & 0.41391 \\
\hline 53 & Dust control measures & 0.33831 \\
\hline 56 & Noise control and light pollution control measures & 0.29750 \\
\hline 33 & Site utilization & 0.25502 \\
\hline 34 & Reasonability of construction layout & 0.23933 \\
\hline 15 & Quotation for sporadic project & 0.19142 \\
\hline 3 & Registered capital & 0.16971 \\
\hline 27 & Quality and quantity of labor & 0.15195 \\
\hline 28 & Material quality & 0.12137 \\
\hline 29 & Mechanical equipment level & 0.09758 \\
\hline 2 & Enterprise size & 0.09738 \\
\hline 8 & Litigation or arbitration & 0.07262 \\
\hline 52 & Personal safety measures & 0.03022 \\
\hline 39 & Proportion of local materials & 0.01088 \\
\hline
\end{tabular}

TABle 3: Effect factors.

\begin{tabular}{|c|c|c|}
\hline Code & Effect factors & Cause degree $(<0)$ \\
\hline 13 & Total bid price & -1.52156 \\
\hline 5 & Financial ability & -1.27824 \\
\hline 30 & Water saving and water resource utilization measures & -1.20028 \\
\hline 35 & Land saving and land resource utilization measures & -1.16909 \\
\hline 37 & Material saving and material resource utilization measures & -1.13391 \\
\hline 41 & Energy saving and energy utilization measures & -1.13153 \\
\hline 17 & Payment terms & -1.12063 \\
\hline 26 & Construction plan and technical measures & -0.94114 \\
\hline 49 & Humanistic care for construction laborers & -0.88661 \\
\hline 44 & Organization and coordination capacity & -0.58433 \\
\hline 46 & Green education and cultural construction & -0.57888 \\
\hline 24 & Quality management system and assurance measures & -0.55794 \\
\hline 47 & Health protection for construction laborers & -0.52895 \\
\hline 36 & Proportion of green materials use & -0.43555 \\
\hline 1 & Qualification level & -0.40013 \\
\hline 7 & Contract performance & -0.38400 \\
\hline 9 & Past excellent engineering performance & -0.36277 \\
\hline 31 & New water-saving technology implementation plan & -0.29462 \\
\hline 32 & Safe water implementation plan & -0.26550 \\
\hline 14 & Unit price of main items & -0.21503 \\
\hline 42 & New energy-saving technology implementation plan & -0.18627 \\
\hline 4 & Working capital & -0.16838 \\
\hline 6 & Financial soundness & -0.15403 \\
\hline 22 & Duration reasonability & -0.15248 \\
\hline 10 & Construction in progress and new undertakings & -0.06794 \\
\hline 51 & Safety measures for mechanical facilities & -0.03404 \\
\hline 38 & Proportion of recyclable materials reuse & -0.02605 \\
\hline
\end{tabular}


TABle 4: Key influential factors.

\begin{tabular}{lcc}
\hline Code & Key influential factors & Center degree \\
\hline 13 & Total bid price & 3.14606 \\
21 & Construction period & 3.10734 \\
12 & Green construction demonstration project & 3.07292 \\
45 & Green construction management system & 3.03599 \\
5 & Financial ability & 3.03586 \\
30 & Water saving and water resource utilization measures & 3.00386 \\
35 & Land saving and land resource utilization measures & 2.99154 \\
37 & Material saving and material resource utilization measures \\
41 & Energy saving and energy utilization measures \\
16 & Reasonability of quotation composition & 2.97797 \\
17 & Payment terms & 2.97706 \\
18 & Environmental governance costs \\
19 & Green investment costs & 2.97614 \\
23 & Construction schedule and guarantee measures \\
26 & Construction plan and technical measures \\
11 & Construction experience of similar project & 2.97293 \\
49 & Humanistic care for construction laborers \\
50 & Safety management system and measures \\
20 & Full life cycle operating costs \\
43 & Planning and control capacity \\
& Average value of center degrees of 56 factors & 2.95176 \\
& & 2.94286 \\
& & 2.91643 \\
\end{tabular}

method to obtain research data of the influence degree between each pair of factors to construct direct-relation matrix. However, as for many complex problems with lots of influential factors, it is difficult to obtain data of the influence degree between each pair of factors to construct direct-relation matrix through questionnaire surveys or experts scoring method, which greatly limits the application scope of the DEMATEL method. In addition, the use of questionnaire surveys or expert scoring method to obtain the influence degree between each pair of factors is highly dependent on the knowledge and experience of the survey participants, which relatively affects the objectivity and reliability of the research conclusions. Based on the DEMATEL method, BP neural network is introduced to determine the direct-relation matrix, optimizing the traditional DEMATEL method. This paper uses the BP-DEMATEL model to systematically analyze the cause-effect relationship between factors and identify key influential factors, further optimizing the structure of the bid evaluation system. BP-DEMATEL model replaces the traditional DEMATEL method of using questionnaire surveys or expert scoring methods to obtain research data of the influence degree between each pair of factors, expanding the application scope of the traditional DEMATEL method. BPDEMATEL model maintains the advantages of the traditional DEMATEL method and uses BP neural network to determine direct-relation matrix. This model makes the research conclusions more objective and reliable and provides a reference for the government to implement green procurement in the field of public project.

\section{Conclusions}

\subsection{Theoretical Contribution}

(1) The 20 key influential factors of bid evaluation in government public project green procurement identified in this paper have enriched and perfected the theoretical and practical research in the field of government public project green procurement.

The current research on green procurement is mainly for government procurement and manufacturing procurement, and the research on green supplier selection mainly focuses on goods, while research focusing on projects of government green procurement is rare. In the green procurement management of public project, the selection of green bidders is the key to improve the government green procurement performance and public project green performance. However, the Chinese government procurement system lacks systematic and complete standards of bid evaluation in public project green procurement. Therefore, identifying the key influential factors of bid evaluation in government public project green procurement is of great significance for promoting the construction of government public project green procurement system. This paper uses BP-DEMATEL model to identify key influential factors base on the index system of influential factors of bid evaluation in government public project green procurement, further optimizing the structure of the bid evaluation system. Eventually, 20 key influential factors of bid evaluation in government public project green procurement identified are total bid price, construction period, green construction demonstration project, green construction management system, financial ability, water saving and water resource utilization measures, land saving and land resource utilization measures, material saving and material resource utilization measures, energy saving and energy utilization measures, reasonability of quotation composition, payment terms, environmental governance costs, green investment costs, construction schedule and guarantee measures, construction plan and technical measures, construction experience of similar project, humanistic care for construction laborers, safety 
management system and measures, full life cycle operating costs, and planning and control capacity. The research results have enriched and perfected the theoretical and practical research in the field of government public project green procurement.

(2) The BP-DEMATEL model established in this paper is effectively solving the defects of traditional DEMATEL method that the method is too subjective and tedious when obtaining the influence degree between each pair of factors to construct direct-relation matrix through questionnaire surveys or expert scoring method, thus expanding the scope of the application of the DEMATEL method.

The traditional DEMATEL method depends on questionnaire surveys or expert scoring method to obtain research data of the influence degree between each pair of factors to construct direct-relation matrix. However, as for many complex problems with lots of influential factors, it is difficult to obtain data of the influence degree between each pair of factors to construct direct-relation matrix through questionnaire surveys or experts scoring method, which greatly limits the application scope of the DEMATEL method. In addition, the use of questionnaire surveys or expert scoring method to obtain the influence degree between each pair of factors is highly dependent on the knowledge and experience of the survey participants, which relatively affects the objectivity and reliability of the research conclusions. Based on the DEMATEL method, BP neural network is introduced to determine the direct-relation matrix, optimizing the traditional DEMATEL method. This paper uses the BP-DEMATEL model to systematically analyze the cause-effect relationship between factors and identify key influential factors, further optimizing the structure of the bid evaluation system and providing new methods and ideas for identifying key influential factors of bid evaluation in government public project green procurement. The BP-DEMATEL model effectively solves the defects of traditional DEMATEL method that the method is too subjective and tedious when obtaining the influence degree between each pair of factors to construct direct-relation matrix through questionnaire surveys or expert scoring method, thus expanding the scope of the application of the DEMATEL method.

\subsection{Limitations and Future Research}

(1) The key influential factors of bid evaluation in government public project green procurement need further improvement.

The key influential factors identified in this paper are scientific and systematic. With the rapid green development of economy and society, new indicators can be added based on the index system of influential factors of bid evaluation in government public project green procurement in the future. Under continuous revision and improvement, more comprehensive and systematic key influential factors can be identified.
(2) Research on relation map can be introduced in the future.

The DEMATEL method is an important method for system factor analysis and identification; however it is too subjective and tedious when obtaining the influence degree between each pair of factors to construct direct-relation matrix through questionnaire surveys or expert scoring method. To solve this defect, the BP-DEMATEL model is constructed in this paper. But there remains certain limitation that the BP-DEMATEL model is only suitable for the case where the output is known. It is worth mentioning that the relation map (RM) can be introduced to BP-DEMATEL model in future research. The relation map is a directed graph composed of points, directed edges, and weights, points represent influential factors, directed edges represent the influence of one influential factor on another influential factor, and weights of the directed edges represent the strength of the influence. With the assistance of RM, the RM-BP-DEMATEL can be constructed; thus the directrelation matrix of the factors can be obtained through the actual data of the system factors.

\section{Data Availability}

The data used to support the findings of this study are available from the corresponding author upon request.

\section{Conflicts of Interest}

The authors declare no conflicts of interest.

\section{Acknowledgments}

This work was supported by the National Natural Science Foundation of China (Grant no. 71904046).

\section{References}

[1] J. Liu, J. Xue, L. Yang, and B. Shi, "Enhancing green public procurement practices in local governments: Chinese evidence based on a new research framework," Journal of Cleaner Production, vol. 211, pp. 842-854, 2019.

[2] X. Wei, C. S. Chen, and X. D. Li, "Analysis on the legal applicability of government procurement project -Focusing on the application of Article 7 of the regulations for the implementation of the government procurement law," China Government Procurement, vol. 16, no. 8, pp. 77-80, 2016.

[3] T. Mao, Green Procurement System Needs to Be Improved Urgently, China Environmental News, Beijing, China, 2016.

[4] B. Q. Qi, Y. Li, and Q. Shi, "Countermeasures and recommendations for developing China's green purchasing of engineering construction project," Construction Economy, vol. 30, no. 2, pp. 37-39, 2009.

[5] X. F. Lu, Research on Government green Procurement," Doctor Degree Thesis, Wuhan University of Technology, Wuhan, China, 2008.

[6] B. H. Rao and J. Y. Chen, "Literature review of government green procurement," China Management Informationization, vol. 18, no. 17, pp. 181-184, 2015.

[7] J. Liu, Y. Ma, A. Appolloni, and W. Cheng, "How external stakeholders drive the green public procurement practice? An 
organizational learning perspective," Journal of Public Procurement, vol. 21, no. 2, pp. 138-166, 2021.

[8] Y. Ma, Y. Liu, A. Appolloni, and J. Liu, "Does green public procurement encourage firm's environmental certification practice? The mediation role of top management support," Corporate Social Responsibility and Environmental Management, vol. 28, no. 3, pp. 1002-1017, 2021.

[9] S. A. S. Haeri and J. Rezaei, "A grey-based green supplier selection model for uncertain environments," Journal of Cleaner Production, vol. 221, pp. 768-784, 2019.

[10] M. M. de Boer and L. D. Boer, "Implementing life cycle assessment in green supplier selection: a systematic review and conceptual model," Journal of Cleaner Production, vol. 229, pp. 1198-1210, 2019.

[11] H. X. Gao, Y. B. Ju, E. D. R. S. Gonzalez, and W. K. Zhang, "Green supplier selection in electronics manufacturing: an approach based on consensus decision making," Journal of Cleaner Production, vol. 245, Article ID 118781, 2020.

[12] Q. Wu, L. Zhou, Y. Chen, and H. Chen, "An integrated approach to green supplier selection based on the interval type-2 fuzzy best-worst and extended VIKOR methods," Information Sciences, vol. 502, pp. 394-417, 2019.

[13] C.-Y. Duan, H.-C. Liu, L.-J. Zhang, and H. Shi, "An extended alternative queuing method with linguistic Z-numbers and its application for green supplier selection and order allocation," International Journal of Fuzzy Systems, vol. 21, no. 8, pp. 2510-2523, 2019.

[14] S. Gupta, U. Soni, and G. Kumar, "Green supplier selection using multi-criterion decision making under fuzzy environment: a case study in automotive industry," Computers \& Industrial Engineering, vol. 136, pp. 663-680, 2019.

[15] Y. Yan, A. C. Pan, and Z. C. Li, "Green supplier selection under uncertain delivery for equipment manufacturing enterprises," Industrial Engineering \& Management, vol. 24, pp. 9-15, 2019.

[16] S. B. Zhang, H. Song, and H. Li, "A new perspective of green supply chain management: an exploratory study of green procurement model based on the linkage of government and enterprise," Theory Horizon, vol. 29, no. 3, pp. 174-178, 2013.

[17] Q. H. Zhu and F. Q. Tian, "Empirical study on barriers to implementing green government procurement," ScienceTechnology and Management, vol. 13, no. 2, pp. 25-31, 2011.

[18] J. Tian and Z. L. Zhang, "Research on the restrictive factors of Chinese government green procurement based on ISM," Journal of Northwestern Polytechnical University, vol. 34, no. 3, pp. 39-43+80, 2014.

[19] Q. Wang, R. J. Zhang, and J. Q. Liu, "Price/time/intellectual efficiency of procurement: uncovering the related factors in Chinese public authorities," Journal of Purchasing and Supply Management, vol. 26, no. 3, Article ID 100622, 2020.

[20] J. G. Wang and X. Zou, "Research on government green procurement system," Journal of Zhengzhou University (Philosophy and Social Sciences Edition), vol. 50, no. 6, pp. 30-34, 2017.

[21] W. L. Yang and Z. Cheng, "A discussion on China's engineering government procurement system under the background of GPA," China Government Procurement, vol. 18, no. 6, pp. 31-33, 2018.

[22] J. Wang, Research on the Legal System of Chinese Government green Procurement," Master Degree Thesis, Shanxi University of Finance and Economics, Taiyuan, Shanxi, 2018.

[23] G. Xu, "Effect and improvement strategy of government green procurement," Contemporary Economy and Management, vol. 33, no. 5, pp. 47-51, 2011.
[24] L. Y. Zhan, M. T. Ju, and J. Yang, Suggestions on improving Chinese green public procurement policies" Ecological Economy, vol. 29, no. 6, pp. 95-98, 2013.

[25] C. L. Sun and J. Mu, "Analysis of green purchasing policy of supply chain Based on PEF - The practice and enlightenment of EU," Journal of Tianjin University, vol. 19, no. 1, pp. 7-11, 2017.

[26] Y. Y. Li, Q. Wang, and H. Y. Lv, "Policy recommendations on improving green government procurement system in China in the new era," China Government Procurement, vol. 18, no. 3, pp. 33-35, 2018.

[27] B. K. Qi, H. Wang, and X. Liu, "Application of grey clustering method in evaluation of green supplier of construction engineering," Journal of Shenyang Jianzhu University (Social Science), vol. 14, no. 4, pp. 371-375, 2012.

[28] X. Y. Lin, "Selection of green purchase supplier in construction project," Journal of Wuhan University of Technology, vol. 32, no. 6, pp. 1010-1014, 2010.

[29] C. Su, The First green Procurement Guide in the Engineering Field Will Come Out, pp. 7-24, China Government Procurement News, Beijing, China, 2015.

[30] H. L. Li, X. G. Liu, L. Li, and Q. Zhong, "Research on green construction bidding evaluation index system based on comprehensive evaluation method," Construction Economy, vol. 32, no. 5, pp. 96-99, 2011.

[31] H. L. Li, X. G. Liu, and L. Li, "The research of integrated evaluation index system of green construction project," Journal of Shenyang Jianzhu University (Social Science), vol. 14, no. 1, pp. $38-44,2012$.

[32] H. L. Li and J. Li, "Study on the green construction bid evaluation system -Based on multilevel gray evaluation method," Journal of Technical Economics \& Management, vol. 34, no. 1, pp. 20-23, 2013.

[33] X. H. Yang, Research on Contractor Selection for EPC Projects Based on green Concept," Master Degree Thesis, Harbin Industrial University, Harbin, China, 2011.

[34] Y. Li, A Research on Evaluation Method of Building Contractor green Construction Capacity," Master Degree Thesis, Xi'an University of Architecture and Technology, Xi'an, China, 2016.

[35] Y. Zhang, "Construction of green bid evaluation index system of engineering project," Statistics \& Decision, vol. 32, no. 19, pp. 182-185, 2016.

[36] Y. Zhang, "Construction of bid evaluation index system in government public project green procurement in China based on D-S evidence theory," Sustainability, vol. 12, no. 2, 2020.

[37] M. Dalvi-Esfahani, A. Niknafs, D. J. Kuss, M. Nilashi, and S. Afrough, "Social media addiction: applying the DEMATEL approach," Telematics and Informatics, vol. 43, Article ID 101250, 2019.

[38] W. Torbacki and K. Kijewska, "Identifying key performance indicators to be used in Logistics 4.0 and Industry 4.0 for the needs of sustainable municipal logistics by means of the DEMATEL method," Transportation Research Procedia, vol. 39, pp. 534-543, 2019.

[39] Y.S. Wang, Y. W. Liu, J. H. Huang, and Y. B. Zhang, "Analysis on factors influencing the whole-process engineering consulting of construction projects based on DEMATEL method," Journal of Engineering Management, vol. 35, no. 3, pp. 36-40, 2021.

[40] X. H. Liu, J. G. Ma, and F. Li, "Research on the perception measurement and influencing factors of tourism image of Yunnan-Vietnam railway based on DEMATEL Model," Tourism Research, vol. 13, no. 3, pp. 61-74, 2021. 
[41] W. Han, Y. H. Sun, and B. Miao, "A group DEMATEL desionmaking method with incomplete judgment information," Chinese Journal of Management Science, vol. 29, no. 5, pp. 231-239, 2021.

[42] H. Dehghani, A. Hormozi, and M. Nikpour, "Systematic risks assessment of precast concrete canal in irrigation projects using DEMATEL method," International Journal of System Assurance Engineering and Management, vol. 13, no. 1, pp. 123-130, 2021.

[43] H. X. Li, J. Q. Zhang, L. Chen, and H. Z. Fan, "Research on coal mine safety management level evaluation based on AHPDEMATEL," Mining Research and Development, vol. 41, no. 4, pp. 118-123, 2021.

[44] Y. H. Jian and Z. P. Cui, "Risk factors for PPP projects of water environment treatment based on fuzzy-DEMATEL method," Journal of Economics of Water Resources, vol. 39, no. 3, pp. 62-68+87, 2021.

[45] S. F. Li, M. Shi, and L. Yan, "Analysis on the factors affecting the reform of China's environment from grey to blue supply side -Empirical analysis based on Fuzzy-DEMATEL," Mathematics in Practice and Theory, vol. 51, no. 6, pp. 10-20, 2021.

[46] C. E. Aparecida-Regiani, T. Madjid, T. C. Carla-Schwengber, B. Marina, and P. Istefani-Carísio, "A grey-DEMATEL approach for analyzing factors critical to the implementation of reverse logistics in the pharmaceutical care process," Environmental Science and Pollution Research, vol. 28, no. 11, pp. 14156-14176, 2021.

[47] H. Liu, H. Long, and X. Li, "Identification of critical factors in construction and demolition waste recycling by the greyDEMATEL approach: a Chinese perspective," Environmental Science and Pollution Research International, vol. 27, no. 25, pp. 8507-8525, 2020.

[48] F. W. Wang, Y. S. Xu, Z. K. Wang, Z. X. Yin, and Y. Ma, "Ways to choose safety indicators for the heavy-duty ocean going ships navigating on the high seas based on the DEMATEL-ANP method," Journal of Safety and Environment, vol. 21, no. 1, pp. 62-69, 2021.

[49] J. Zhao, L. H. Du, and T. K. Li, "Risk identification of collaborative $\mathrm{R} \& \mathrm{D}$ projects in the military and civilian integration field based on COWA-DEMATEL," Modernization of Management, vol. 41, no. 3, pp. 99-103, 2021.

[50] S. S. Zhou, N. Zhang, X. J. Zhang, Q. Y. Liu, and M. Li, "Research on risk decision of underground pipe gallery construction based on DEMATEL-TOPSIS method," Journal of Qingdao Technological University, vol. 42, no. 2, pp. 119-127+148, 2021.

[51] Y. Y. Yuan, Z. S. Xu, and Y. X. Zhang, "The DEMATELCOPRAS hybrid method under probabilistic linguistic environment and its application in Third Party Logistics provider selection," Fuzzy Optimization and Decision Making, vol. 20, pp. 1-20, 2021.

[52] F. Lin, P. Wu, and Y. D. Xu, "Investigation of factors influencing the construction safety of high-speed railway stations based on DEMATEL and ISM," Advances in Civil Engineering, vol. 2021, Article ID 9954018, 2021.

[53] S. R. Li, M. S. Wang, J. X. Chai, Z. L. Zhao, and L. H. Zhang, "The Study on influencing factors of the power grid green development based on Dematel-Ism model," Mathematics in Practice and Theory, vol. 51, no. 8, pp. 283-294, 2021.

[54] B. S. Zhang and Y. Y. Ren, "Research on the construction of index system of natural gas price influencing factors," Price: Theory and Practice, vol. 40, no. 11, pp. 64-67+183, 2020.
[55] B. H. Jia, S. Y. Shi, and Y. X. Wang, "Risk factors analysis of the wheel brake system based on the improved DEMATELISM," Journal of Safety and Environment, vol. 21, no. 2, pp. 506-512, 2021.

[56] Y. Lei and H. Yang, "Research on factors influencing the highquality development of red tourist attractions: based on the DEMATEL-ISM-MICMAC method," Journal of Yunnan University of Finance and Economics, vol. 37, no. 6, pp. 100-110, 2021.

[57] Q. Cui, C. Y. Wu, and H. B. Kuang, "Influencing factors research of airports competitiveness based on BP-DEMATEL model," System Engineering Theory and Practice, vol. 33, no. 6, pp. 1471-1478, 2013.

[58] X. N. Qin and X. L. Lu, "A BP-DEMATEL model based research of the factors that affect coastal urban ecological security system," Management Review, vol. 27, no. 5, pp. 48-58, 2015.

[59] Q. Cheng, B. L. Yang, H. B. Xu, and D. F. Liu, "Research on the influence factors of original innovation environment," Studies in Science of Science, vol. 34, no. 4, pp. 591-600, 2016.

[60] Q. Zhang and C. H. Zhu, "Research of influence factors for China's municipalities Entrepreneurial environment based on BP-DEMATEL," Journal of Industrial Technological Economics, vol. 37, no. 10, pp. 67-74, 2018.

[61] Y. Chang and Y. J. Xue, "Research on the influencing factors of network innovation environment -An empirical analysis based on BP-DEMATEL model," Enterprise Economy, vol. 40, no. 5, pp. 126-133, 2019.

[62] E. Fontela and A. Gabus, The DEMATEL Observer, Battelle Geneva Research Center, Geneva, Switzerland, 1976.

[63] A. S. Weigend, B. A. Huberman, and D. E. Rumelhart, "Predicting the future: a connectionist approach," International Journal of Neural Systems, vol. 01, no. 03, pp. 193-209, 1990. 